NASA/TM-1998-206614

\title{
Bubble Formation and Detachment in Liquid Flow Under Normal and Reduced Gravity
}

Henry K. Nahra

Lewis Research Center, Cleveland, Ohio

Y. Kamotani

Case Western Reserve University, Cleveland, Ohio

Prepared for the

36th Aerospace Sciences Meeting \& Exhibit

sponsored by the American Institute of Aeronautics and Astronautics

Reno, Nevada, January 12-15, 1998

National Aeronautics and

Space Administration

Lewis Research Center 
Available from

NASA Center for Aerospace Information 800 Elkridge Landing Road Linthicum Heights, MD 21090-2934 Price Code: A03
National Technical Information Service 5287 Port Royal Road Springfield, VA 22100 Price Code: A03 


\section{Bubble Formation and Detachment in Liquid Flow Under Normal and Reduced Gravity}

Henry K. Nahra

Microgravity Fluid Physics Branch

Microgravity Science Division

NASA-LERC

Cleveland, $\mathrm{OH}$

\section{Abstract}

Two-phase flows are present in a wide variety of applications for spacecraft thermal control systems design. Bubble formation and detachment is an integral part of the two-phase flow science. The authors' objective is to experimentally investigate the effects of liquid cross velocity, gas velocity, and nozzle diameter on the bubble diameter at detachment under reduced and normal gravity and under relatively low gas flow rates. Results from ground $(1 \mathrm{~g})$ and reduced gravity experiments will be presented in this paper. For the $1 \mathrm{~g}$ experiment, a flow loop was designed and built to accommodate a range of liquid and gas flow rates. The reduced gravity experiment was conducted on the NASA DC-9 reduced gravity platform using the two-phase flow loop qualified for operation on the low-gravity platform. Flow visualization is accomplished using a high speed 500 frames/s camera. The results suggest that the existence of buoyancy force contributes to the faster detachment of bubbles. Buoyancy helps the detachment process which results in smaller bubbles being formed. In reduced gravity, although drag force is present, the virtual non-existence of buoyant force results in larger bubbles and longer times for detachment. Theoretical predictions are also presented in this paper and seem to agree with the experimental results.

\section{Introduction}

${ }^{1}$ Copyright $\odot 1998$ by the American Institute of Aeronautics and Astronautics, Inc. No copyright is asserted in the United States under Title 17, U.S. Code. The U.S. Government has a royalty-free license to exercise all rights under the copyright claimed herein for Governmental Purposes. All other rights are reserved by the copyright owner.

\author{
Y. Kamotani \\ Department of Mechanical \& Aerospace \\ Engineering \\ Case Western Reserve University
}

Cleveland, $\mathrm{OH}$

The power requirements for current and future space missions are increasing due to rising power demand. More efficient and larger capacity thermal control systems for space applications are, therefore, needed to handle the increasing power requirements. Two-phase flow thermal control systems provide more effective thermal transport in spacecrafts ${ }^{1}$ due to the higher latent heat of vaporization of fluids when compared to their sensible heat. Two-phase flow phenomena are encountered in space propulsion systems, thermal control of power generation and distribution subsystems, cryogenic liquid transfer and storage systems, life support systems, and systems related to commercial development of space programs ${ }^{2,3}$.

Dispersed phase bubble or droplet formation and behavior play an important role in two phase flows. Understanding of such a behavior in microgravity is crucial because of its direct implications to the design of two phase flow systems for large space structure such as the space station.

Understanding the behavior of dispersed bubble in microgravity includes the understanding of bubble formation, its growth, shape, detachment and the forces involved in affecting these processes. Due to the virtual absence of the buoyancy force, detachment of bubbles is very different under microgravity especially at low gas flow rates. One method to help detach forming bubbles is to apply a cross flow where the drag force helps the bubble detachment ${ }^{3}$. The purpose of this work is to experimentally investigate the effects of liquid cross velocity, gas velocity, and nozzle diameter on the bubble diameter at detachment under reduced and normal gravity.

\section{Experimental}




\subsection{Ground Flow Loop}

The ground $(1 \mathrm{~g})$ flow loop was built in order to perform the Bubble Formation and Detachment in a Liquid Cross Flow experiment. A schematic is shown in Figure 1. A centrifugal pump was used to establish the liquid flow in a square $2.54 \mathrm{~cm}\left(1^{\prime \prime}\right)$ hydraulic diameter channel. The liquid flow rate was measured with two liquid flow meter connected in parallel and used depending on the liquid flow rates which ranged from 0 to 6000 $\mathrm{ml} / \mathrm{min}$. The gas flow rate was at first established from a pressurized air bottle. However, due to the need to establish low liquid air flow rates, a syringe pump was used. The latter established the desired/calibrated rates up to $13 \mathrm{ml} / \mathrm{min}$. The flow channel was constructed from Plexiglass and pressure tested to $2.5810^{6}$ dynes $/ \mathrm{cm}^{2}(37.5$ psi) with no water leaks observed. A bypass loop was also established in order to have better control on the liquid fiow rates. The liquid is pumped into the channel and its flow rate is controlled. The syringe pump is then turned on and allowed to run until sufficient pressure is built in the syringe in order to prevent any liquid backflow into the syringe. Then a gate valve is open to allow the air into the liquid cross flow. Two orifice diameters $(.033 \mathrm{~cm}$ and $.076 \mathrm{~cm}$ ) were used (one at the time) for air injection into the liquid flow. The orifices were flush with the plexiglass surfaces in order to reduce flow disturbances. The $.033 \mathrm{~cm}$ orifice design resembled a converging nozzle whereas the design of the .076 $\mathrm{cm}$ orifice resembled a tube with an inner diameter of $.076 \mathrm{~cm}$. Figure 2 shows a schematic of the two nozzle designs used in the $1 \mathrm{~g}$ and low $\mathrm{g}$ experiments. A high-speed camera (nac 500 or nac 1000) is used to videotape the events of bubble generation and detachment.

\subsection{Low-Gravity Two-Phase Flow Loop}

This flow loop is frequently used for two phase flow experiments requiring low gravity ${ }^{6}$. It consists of a liquid flow subsystem which is composed of a water reservoir made of Plexiglass $₫$ and fitted with a piston which is driven by air pressure provided by air bottle on board of the DC-9 platform. The loop has a gas flow subsystem which provides the gas flow into the liquid in order to establish the various regimes of two-phase flows. Since the existing gas flow system could not accommodate the required low gas flow rates, it was decided to integrate the syringe pump to establish the gas flow rates. The same flow channel was integrated into the loop. The same two orifices/injectors (of diameters .033 and .076 $\mathrm{cm}$ ) were used to generate the air bubbles in the cross flow. Data acquisition is furnished by the two phase flow loop as well. Liquid and gas flow rates as well as acceleration data is written to files in binary format. Flow visualization is accomplished using the same high speed cameras used in the $1 \mathrm{~g}$ ground experiments. Figure 3 shows the arrangement flown on board of the $D C-9$ low gravity platform.

\section{Experimental procedure and Data Analysis}

The procedure for the ground experiment is similar to the one applied in the low gravity environment. The liquid flow is first established, then air is introduced through the orifice nozzle. Several liquid flow rates are accomplished with several gas flow rates for each of the orifices. The recorded video data was analyzed using the TRACKER software 4 commonly used at NASA. This enabled the measurement of the bubble diameter at or very near the detachment point. The measurement is based on a count of pixels and a comparison with an existing scale. These measurements, in addition to Time to Detachment (TTD) measurements were entered in a text/data file. The data file was read by a MATHEMATICA@IM program which calculated the bubble average diameter, the standard deviation of the mean and the mean TTD designated by MTTD.

\section{Prediction of Bubble Diameter at Detachment}

\subsection{Governing Equations}

Prediction of the detachment bubble diameter is accomplished using a force balance on the bubble as it is forming from the nozzle. The coordinate system used in this calculation is illustrated in Figure 4. The force balance is given by the following

$$
\frac{d}{d t}\left(M_{b} \frac{d \bar{S}}{d t}\right)=\sum_{j=1}^{n} \vec{F}_{j}
$$

where $\bar{S}$ is the position vector of the bubble center of mass, $M_{b}$ is the bubble mass and $\vec{F}_{j}$ is the jth force acting on the bubble. The forces acting on the bubble are the drag, the surface tension, the rate of momentum from the gas flow, and the buoyancy forces. The term on the left hand side 
of (1) is defined as the inertia term. The forces are given respectively by the following equations $\mathrm{s}^{3,5}$

$$
\begin{aligned}
& F_{D i}=\frac{1}{2} C_{D} \rho_{c} A U U_{i} \\
& F_{S i}=\pi \sigma D_{N} f(\phi)_{i} \\
& F_{M}=\rho_{d} \frac{4 Q_{d}{ }^{2}}{\pi D_{N}{ }^{2}} \\
& F_{B}=\left(\rho_{c}-\rho_{d}\right) V_{b} g
\end{aligned}
$$

where the subscripts $c$ and $d$ designate the continuous and dispersed phases respectively, the subscripts $B$ and $b$ designate the buoyancy and bubble, the subscript $i$ designates the ith direction ( $x, y$ or $z$ ) in Cartesian coordinates, $C_{D}$ is the drag coefficient, $A$ is the effective area, $U$ is the relative velocity, $D_{N}$ is the nozzle diameter, $f(\phi)_{i}$ is the surface tension function that changes with the bubble inclination $\phi$ (as shown in Figure 4) and which depends on the Cartesian coordinates, $Q_{d}$ is the gas flow rate, and $V_{0}$ is the bubble volume. The last two forces (4) and (5) point in the direction +y opposite to the direction of $g$ which is defined in this calculation as $-y$. The direction of the cross flow velocity $U_{L s}$ is defined as $+x$ direction. Equation (1) is decomposed into its components which are $X(t), Y(t)$, and $Z(t)$. Since the bubble mass $M_{b}$ is changing with time, an added mass coefficient ${ }^{3}$ results from the expansion and the displacement of the surrounding fluid. In this calculation, an added mass coefficient ${ }^{7} C_{M}=\frac{11}{16}$ was used in the inertial terms of the equation of motion. The nonlinear ordinary second order coupled differential equations for the expansion and detachment phases were solved using the NDSOLVE routine in MATHEMATICA@TM.

\subsection{Expansion Phase}

Two phases are identified in the process of bubble formation. The first is the expansion phase whose end is defined by the minimum of the times $t_{x}$ and $t_{y}$ the first of which satisfies the following criteria,

$\sqrt{X(t)^{2}+Z(t)^{2}}-\frac{1}{2}\left(D_{B}(t)+D_{N}\right) \geq 0(6)$ and the second of which satisfies the force balance in the $y$ direction. In other words, $t_{x}$ and $t_{y}$ are the root solutions of equation 6 and the $y$ direction force balance and the end of the bubble formation phase is given by $t_{e}=$ Min $\left[t_{x}, t_{y}\right]$. During this phase, $Y(t)$ was taken to equal $1 / 2 D_{B}(t)$ which can be calculated from a simple expansion process where it is proportional to $t^{1 / 3}$. The $X(t)$ and $Z(t)$ components are solved simultaneously.
This amounted to solving a system of second order nonlinear ordinary differential equations. After obtaining $X(t)$ and $Z(t)$, criterion (6) and the $y$ direction force balance are checked. If $t_{x}<t_{y}$, then the bubble is detached before starting the detachment phase. If $t_{y}<t_{x}$, then the upward forces on the bubble are sufficient to lift the bubble which begins developing a neck. This begins the detachment phase.

\subsection{Detachment Phase}

In this phase the three components of the equation of motion were solve simultaneously. The initial conditions were the same as the conditions at the end of the expansion phase. From the $X(t), Y(t)$ and $Z(t)$ functions, two detachment criteria are evaluated. The first is equation (6) and the second is based on the neck length and is given by ${ }^{3}$

$$
\sqrt{X(t)^{2}+Y(t)^{2}+Z(t)^{2}}-\left(\frac{1}{2} D_{B}(t)+D_{N}\right) \geq 0
$$

After determining the times at which equations (6) and (7) are satisfied, a geometric average of the two times is determined and then used to evaluate the detachment diameter. The drag coefficient which is a function of the bubble Reynolds number is iterated in the solution of both the expansion and detachment phase.

\section{Results-Comparison of Predicted and Measured Bubble Diameter at Detachment} The results from the experiments and the analytical predictions are presented in this section for the $1 \mathrm{~g}$ and low $\mathrm{g}$ environments respectively.

\subsection{Full g results}

Comparison between analytical predictions and experimental results under full gravity is shown in Figure 5 for $D_{N}=.033 \mathrm{~cm}$ and $D_{N}=.076 \mathrm{~cm}$. From the lower set of data $\left(D_{N}=.033 \mathrm{~cm}\right)$, the \% difference between experimental and predicted diameters ranges from 9 to $16 \%$. From the higher set of data $\left(D_{N}=.076 \mathrm{~cm}\right)$, the difference ranges between 4 and $14 \%$. The air flow rate in figure 5 is 8 and $13 \mathrm{ml} / \mathrm{min}$ corresponding respectively to $\mathrm{D}_{\mathrm{N}}=.033$ and $.076 \mathrm{~cm}$. Overall, the prediction compared reasonably well with experimental results under full gravity. The predictions of detachment diameter for superficial velocities less that $4.5 \mathrm{~cm} / \mathrm{s}$ were not possible due to an instability in the solution. The two aforementioned detachment criteria during the detachment phase have no solutions for $U_{L S}<\sim 4.5 \mathrm{~cm} / \mathrm{s}$. As a result, 
the predicted curve stopped at the data point prior to $4.5 \mathrm{~cm} / \mathrm{s}$, i.e. at $5.82 \mathrm{~cm} / \mathrm{s}$.

\subsection{Low g results}

Figure 6 shows the experimental and predicted bubble diameters at detachment for $Q_{d}=8 \mathrm{ml} / \mathrm{min}$, $D_{N}=.033 \mathrm{~cm}$ (the lower curve and data) and $D_{N}=.076 \mathrm{~cm}$ (the upper curve and data)

respectively. From the plotted data of Figure 6 , the difference between experiment and prediction ranged from 1 to $13 \%$ for $D_{N}=.033 \mathrm{~cm}$ and from 4 to $15 \%$ for $D_{N}=.076 \mathrm{~cm}$. As under the full gravity, the prediction compared reasonably well with the experimental results.

Figure 7 shows a plot of the predicted Time To Detachment (TTD) vs. $U_{L S}$ for low and full gravity. The predicted TTD is higher under low gravity due to the lack of buoyancy force. It is apparent also that the TTD of the low $\mathrm{g}$ case is three times as large as the $1 \mathrm{~g}$ case. Figure 8 shows the experimental MTTD and calculated TTD as a function of the cross liquid velocity for $Q_{d}=3.8$ $\mathrm{ml} / \mathrm{min}$ and $D_{\mathrm{N}}=.076 \mathrm{~cm}$. The difference between MTTD and TTD ranged from 10 to $18 \%$. Figure 9 shows a comparison of the bubble growth and detachment under $1 \mathrm{~g}(\mathrm{a})$ and in low $\mathrm{g}(\mathrm{b})$ for $Q_{c}=4000 \mathrm{ml} / \mathrm{min}, D_{N}=.033 \mathrm{~cm}, Q_{d}=10 \mathrm{ml} / \mathrm{min}$. The traces of the developing bubbles were captured from exactly the same size digitized video images. It is apparent that lack of buoyancy results in larger, more spherical bubbles produced by the $.033 \mathrm{~cm}$ nozzle.

\subsection{Discussion}

As shown from the aforementioned results, the agreement between the experimental and calculated detachment bubble diameter was reasonably good. The agreement was better in the low $\mathrm{g}$ results than under the full $\mathrm{g}$. Also the agreement between experiment and prediction is better in the high liquid cross velocity than in the lower cross velocity region. From these observations, it can be seen that the model solved here predicts within $10 \%$ the bubble detachment diameter for the higher liquid cross velocity region under low $g$ setting. The same statement can be made regarding the $1 \mathrm{~g}$ setting, however, we should expect slightly larger uncertainty in the bubble detachment diameter.

\section{Concluding Remarks}

We have shown in this paper the results of ground and low gravity bubble generation and detachment in a liquid cross flow experiment. We have also shown the results of the prediction of the bubble diameter at detachment which was based on a force balance applied on the evolving bubble. The prediction compared well with the experiment with a difference not exceeding $16 \%$ in all the cases studied.

The same arrangement was flown again, however, on the second flight, a flow meter with a set point was used to control the air flow into the liquid cross flow. This air flow controller provided wider range of flow air rates than the syringe. The data is currently being analyzed using the TRACKER software which was used for the first flight. The same model will eventually be applied to compare the predictions with the experimental results.

\section{References}

1. Eastman et.al. "Two phase Fluid Transport for Spacecraft", AFWAL-TR-84-3028.

2. Ostrach S., "Industrial Processes Influenced by Gravity" NASA CR-182140, C-21066-G, 1988.

3. lee-Hwan Kim et.al. "Modeling of Bubble and Drop Formation in Flowing Liquids in Terrestrial and Microgravity Environments," EMAEITR-92-207, Case Western University, Cleveland, $\mathrm{OH}$, May 1992.

4. Klimek R. B., Wright T. W., Sielken R. S., "Color Image Processing and Object Tracking System", NASA TM-107144, February, 1996.

5. leeHwan Kim et.al. "Modeling of Bubble and Drop Formation in Flowing Liquids in Microgravity," AlChE, Vol. 40, No. 1, 1994.

6. McQuillen, J. B., and Neumann, E. S., "TwoPhase Flow Research Using the Learjet Apparatus", NASA TM-106814, May 1995.

7. Kawase, Y., and Ulbrecht, J. J., "Formation of Drops and Bubbles in Flowing Liquids", Ind. Eng. Chem. Process Des. Dev., 20,636, 1981. 


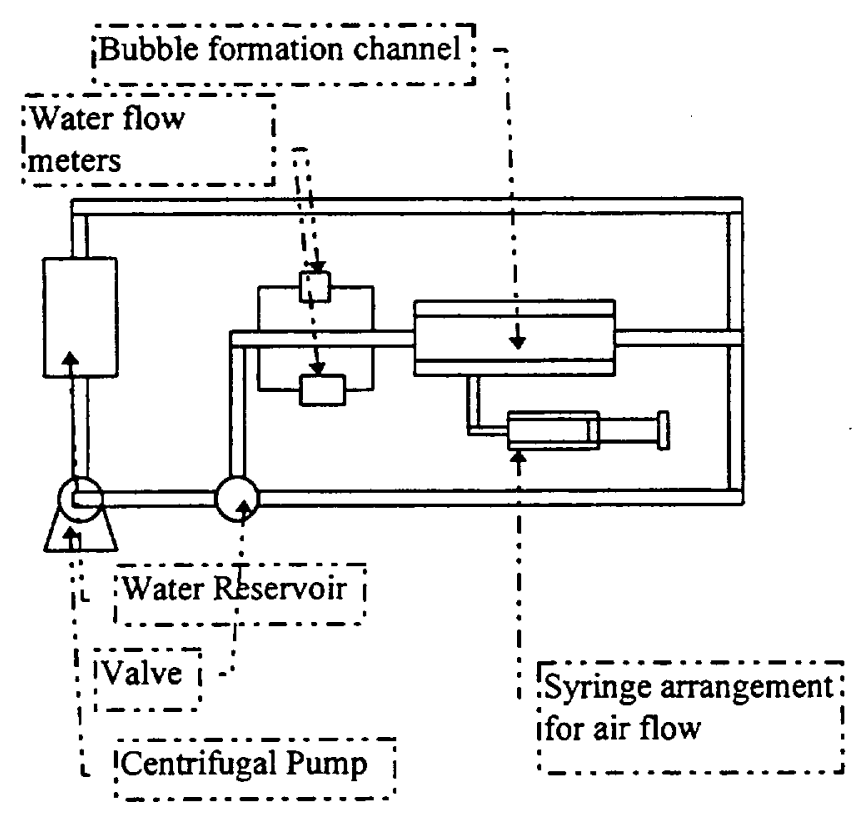

Figure 1. Simplified Schematic of the Ground Flow Loop used for the Bubble Formation and Detachment experiment

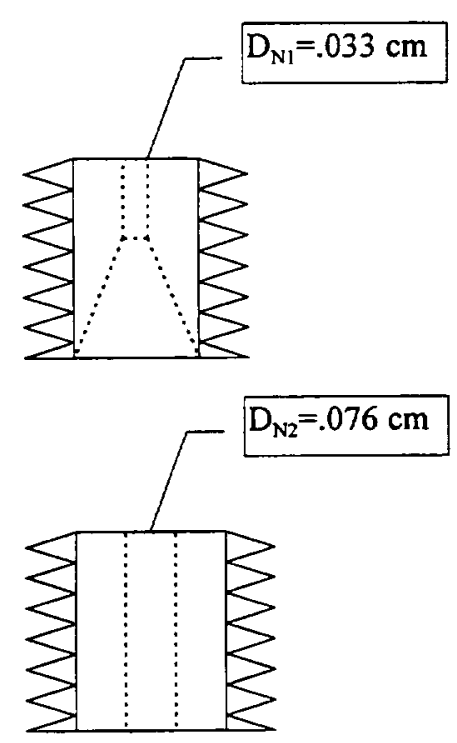

Figure 2. Schematic of air orifice design. The upper is an orifice with a converging nozzle design. The lower is a tubular design.

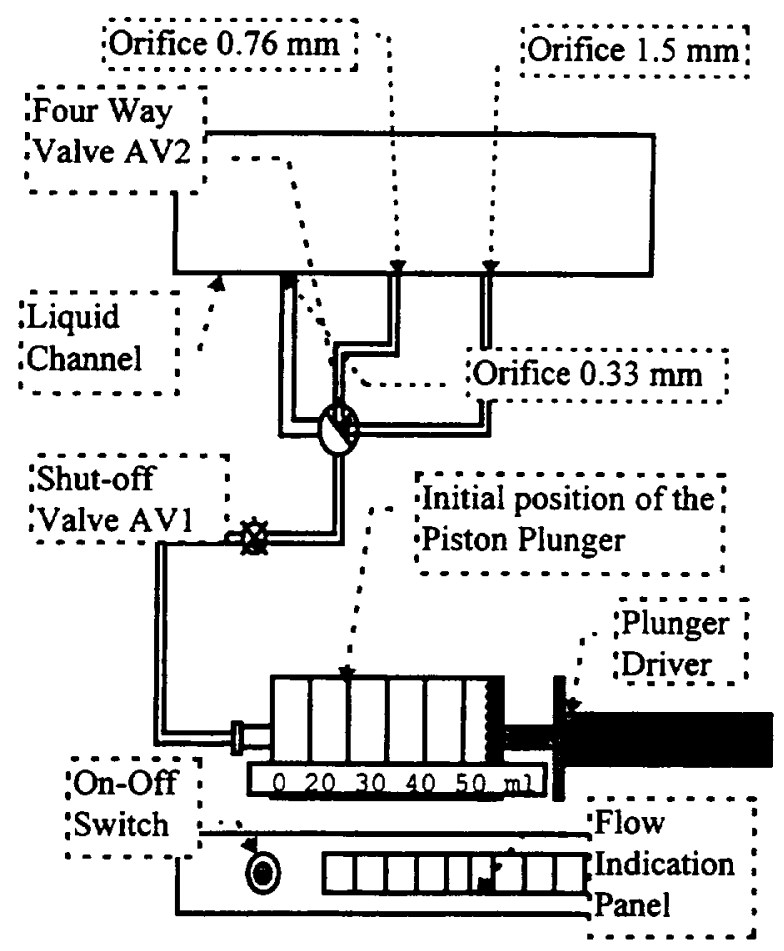

Figure 3. Low gravity flight configuration on board of the DC-9 low gravity platform.

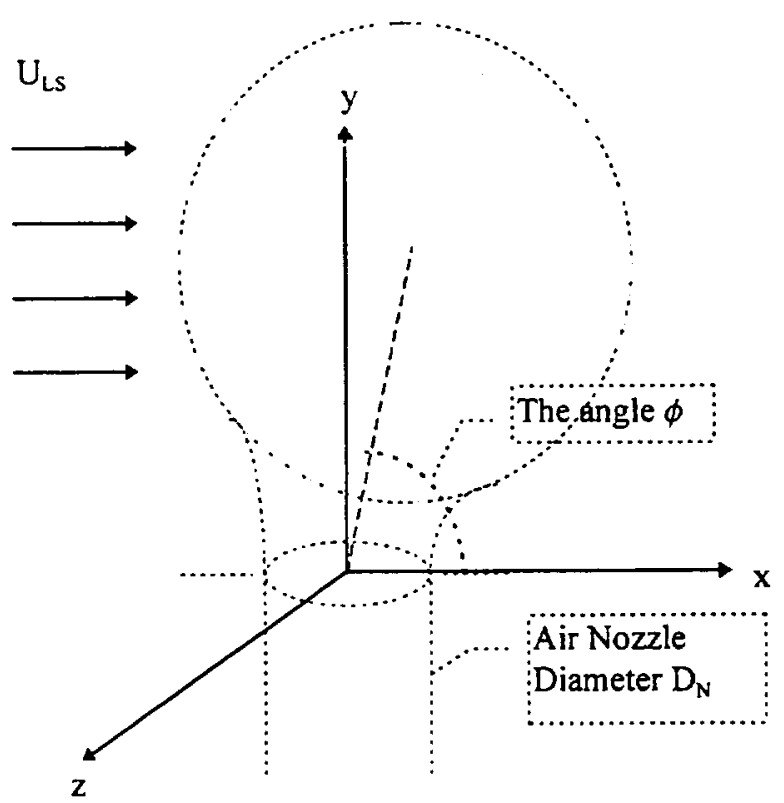

Figure 4. Coordinates and geometry of the Bubble Formation and Detachment in Liquid Cross Flow experiment. $U_{L S}$ is in the $+x$ axis and $g$ in the $-y$ axis. 


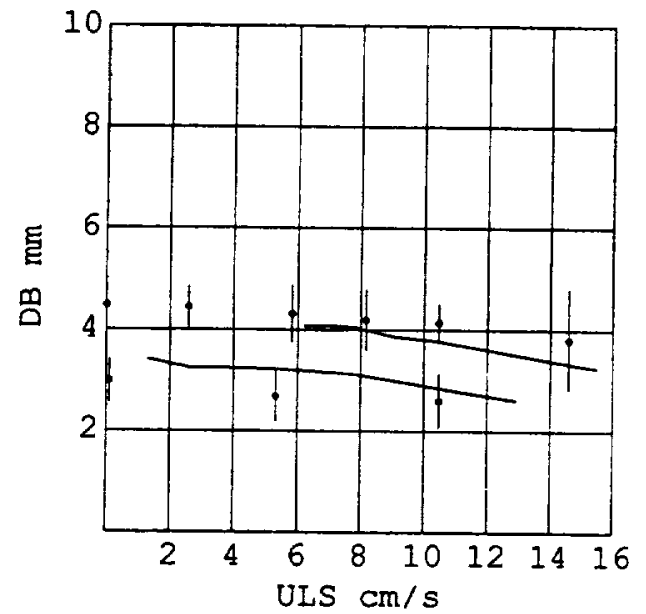

Figure 5. Experimental and predicted detachment diameter results for full $\mathrm{g}$. The upper set of data and the continuous curve correspond to $D_{N}=.076$ $\mathrm{cm}$. The lower set corresponds to $D_{N}=.033 \mathrm{~cm}$.

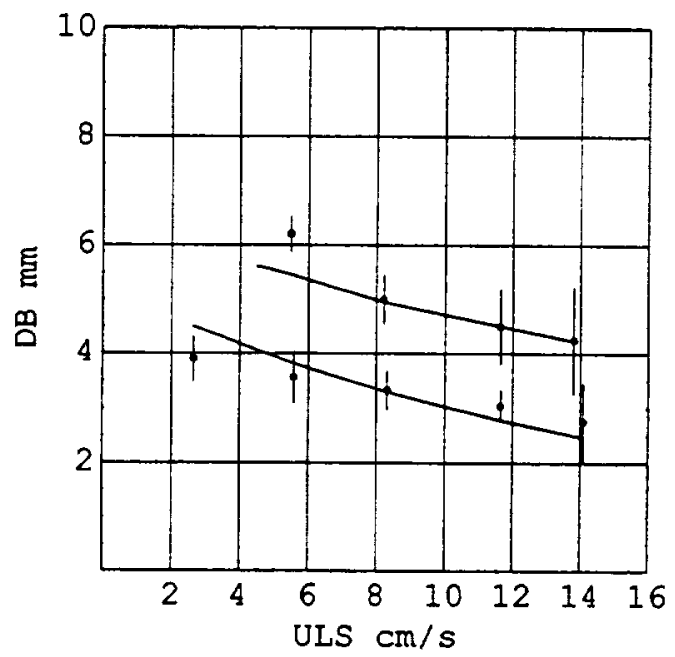

Figure 6. Experimental and predicted detachment diameter results for low $\mathrm{g}$. The upper set of data and the continuous curve correspond to $D_{N}=.076$ $\mathrm{cm}$. The lower set corresponds to $D_{N}=.033 \mathrm{~cm}$.

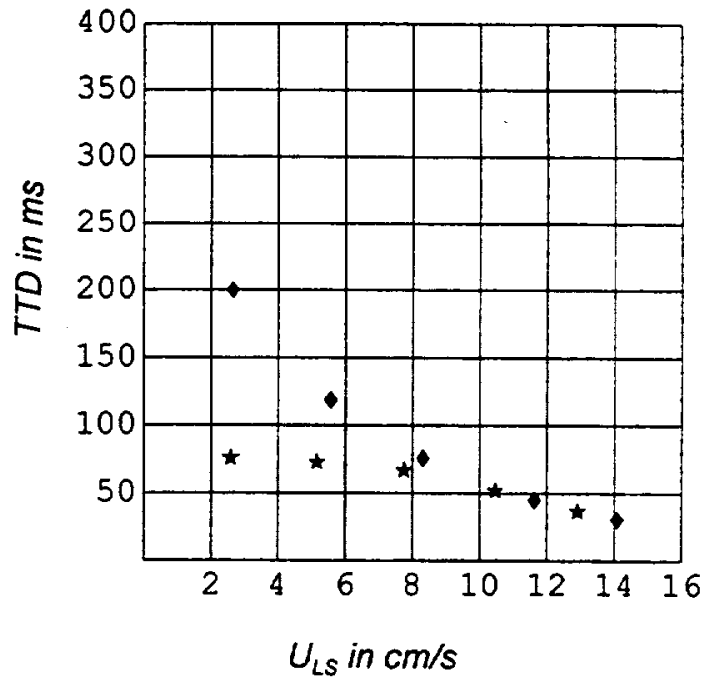

Figure 7. Predicted TTD in $m s$ as a function of $U_{L S}$ for full $g(\star)$ and low $g(\downarrow)$ and for $D_{N}=.033 \mathrm{~cm}$. $Q_{d}$ in this case is $8 \mathrm{ml} / \mathrm{min}$. The higher curve at small $U_{L S}$ corresponds to the low $g$ predicted $T T D$.

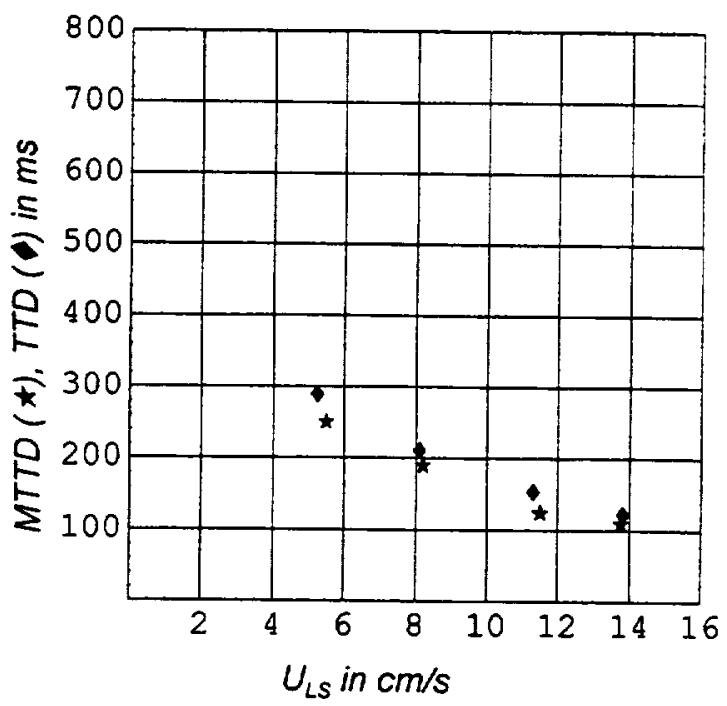

Figure 8. Experimental MTTD ( $\star$ ) and predicted $T T D(\$)$ in $m s$ as a function of the cross liquid velocity for low g. $Q_{d}=3.8 \mathrm{ml} / \mathrm{min}, D_{N}=.076 \mathrm{~cm}$ 


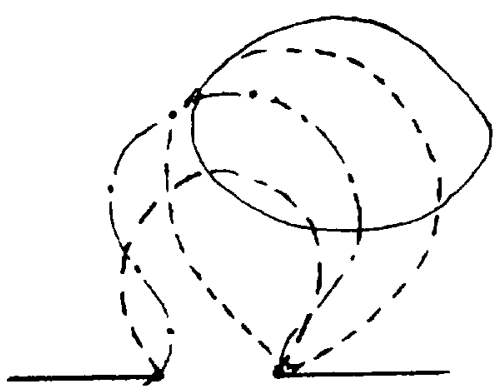

a) $1 \mathrm{~g}$

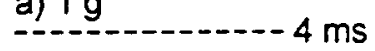

-............... $8 \mathrm{~ms}$

....................... $10 \mathrm{~ms}$

$-12 \mathrm{~ms}$

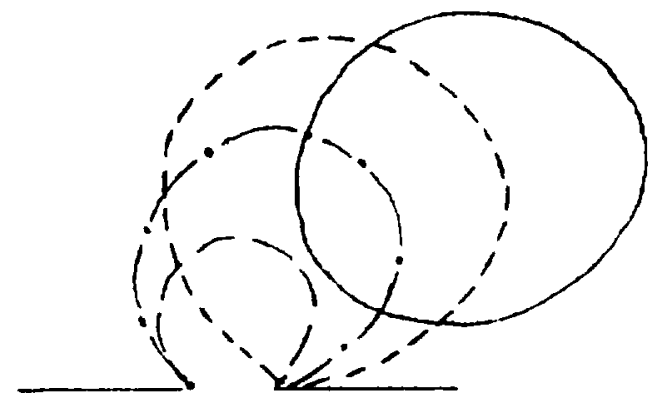

b) Low $g$

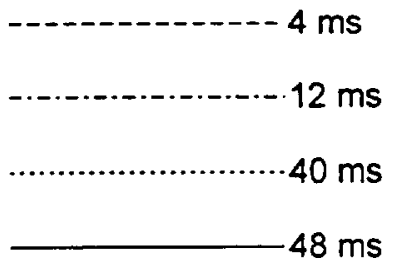

Figure 9. Comparison of bubble growth and detachment under $1 \mathrm{~g} \mathrm{(a)}$ and in low $\mathrm{g}(\mathrm{b})$. $Q_{c}=4000 \mathrm{ml} / \mathrm{min}, D_{N}=.033 \mathrm{~cm}, Q_{d}=10 \mathrm{ml} / \mathrm{min}$. 


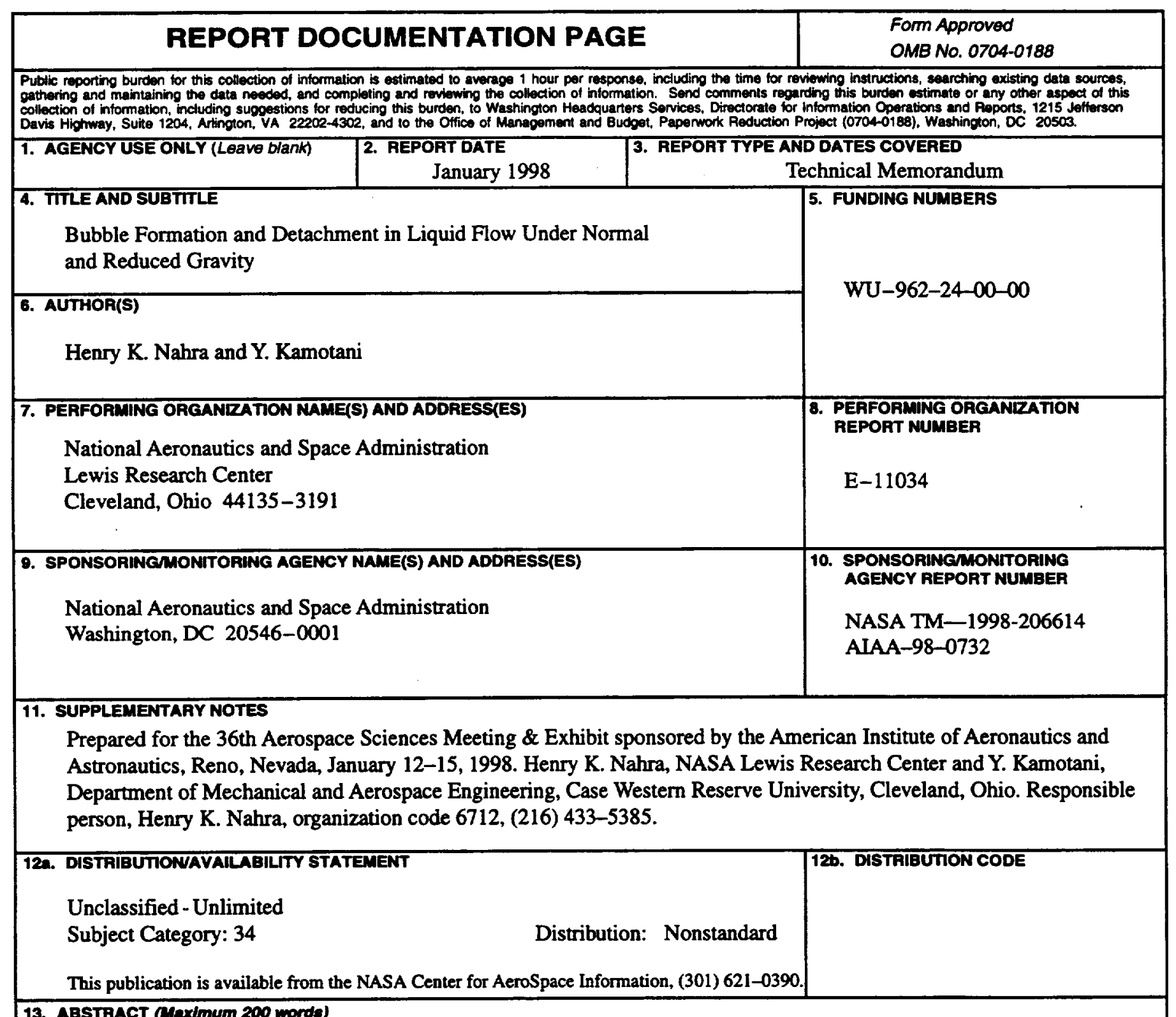

13. ABSTRACT (Meximum 200 words)

Two-phase flows are present in a wide variety of applications for spacecraft thermal control systems design. Bubble formation and detachment is an integral part of the two-phase flow science. The authors objective is to experimentally investigate the effects of liquid cross velocity, gas velocity, and nozzle diameter on the bubble diameter at detachment under reduced and normal gravity and under relatively low gas flow rates. Results from ground $(1 \mathrm{~g})$ and reduced gravity experiments will be presented in this paper. For the $1 \mathrm{~g}$ experiment, a flow loop was designed and built to accommodate a range of liquid and gas flow rates. The reduced gravity experiment was conducted on the NASA DC-9 reduced gravity platform using the two-phase flow loop qualified for operation on the low-gravity platform. Flow visualization is accomplished using a high speed 500 frames/s camera. The results suggest that the existence of buoyancy force contributes to the faster detachment of bubbles. Buoyancy helps the detachment process which results in smaller bubbles being formed. In reduced gravity, although drag force is present, the virtual non-existence of buoyant force results in larger bubbles and longer times for detachment. Theoretical predictions are also presented in this paper and seem to agree with the experimental results.

\begin{tabular}{|c|c|c|}
\hline \multicolumn{3}{|l|}{$\begin{array}{l}\text { 14. SUBJECT TERMS } \\
\text { Bubble; Formation; De }\end{array}$} \\
\hline $\begin{array}{l}\text { 17. SECURITY CLASSIFICATION } \\
\text { OF REPORT } \\
\text { Unclassified }\end{array}$ & $\begin{array}{l}\text { 18. SECURITY CLASSIFICATION } \\
\text { OF THIS PAGE } \\
\text { Unclassified }\end{array}$ & $\begin{array}{l}\text { 19. SECURITY CLASSIFICATION } \\
\text { OF ABSTRACT } \\
\text { Unclassified }\end{array}$ \\
\hline
\end{tabular}

NSN 7540-01-280-5500 